\title{
DO IRREAL AO POÉTICO: AZARIAS, PEQUENO E ÓRFÃO, NAS ASAS DO NDLATI
}

\author{
Elizabeth da Silva Mendonça \\ (Universidade Estadual Paulista)
}

\section{RESUMO}

A amplitude do conceito de pós-colonialismo abriga algumas críticas literárias feitas a partir das produções das nações anteriormente colonizadas pelas metrópoles ocidentais. Pensando nas formulações de Appiah (2007) sobre a contestação que o pós-colonial faz das narrativas legitimadoras anteriores, em nome de um universalismo ético-humanista, podemos observar a literatura de Mia Couto, no conto "O dia em que explodiu o Mabata-bata", do livro Vozes anoitecidas, como um projeto literário que consegue unir o estético ao político. Toda a tradição cultural do moçambicano é apresentada para narrar a história de uma criança órfã, abandonada pelos seus parentes e resgatada, pela sua própria imaginação, de uma morte brutal.

PALAVRAS-CHAVE: Mia Couto, pós-colonialismo, oralidade.

\section{ABSTRACT}

The breadth of the concept of post-colonialism welcome some literary criticism made from the productions of Nations previously colonized by Western metropolises. Thinking in the formulations of Appiah (2007), on the plea that the post-colonial narratives earlier, in name of an ethical-humanist universalism, we can observe the literature of Mia Couto, in the story "O dia em que explodiu Mabata-bata" from the book Vozes Anoitecidas, as a literary project that can unite the aesthetic and the politician. The entire southern Mozambican cultural tradition is presented to narrate the story of an orphaned child, abandoned by his relative and rescued by their own imagination, a brutal death.

KEYWORDS: Mia Couto, post-colonialism, orality. 
Kwame A. Appiah, no capítulo "O pós-colonial e o pós-moderno", do seu livro Na casa de meu pai: a África na filosofia da cultura, afirma que "o pior de todos os erros consiste em julgar o Outro segundo nossos próprios termos" (APPIAH, 2007, p. 195). Partindo dessa afirmação, ao voltarmos o nosso olhar para a África, temos que levar em conta que, nas primeiras produções africanas, após a independência de seus países, o objetivo principal era construir uma África imaginada. Appiah expõe que os escritores dessa época inicial, pós-independência, eram "no Ocidente conhecidos pela África que oferecem; seus compatriotas os conhecem pelo Ocidente que eles apresentam à África e por uma África que eles inventaram para o mundo" (APPIAH, 2007, p. 208). A literatura estava ligada a vontades sócio-políticas num constante jogo de representações. A tradição era escavada e trazida à luz da cena para construir uma África que havia, para esses escritores, sido enterrada pela colonização.

A tradição e aquilo que veio pelas mãos do colonizador, mesmo no seio da cultura popular africana, não causam nenhuma preocupação substancial. Produtos culturais vindos do Ocidente são, a todo momento, usados e mesmo mesclados pela população do continente africano. Essas preocupações dos escritores anticolonialistas não têm significado para tal população que não está preocupada em situar-se no colonialismo ou fora dele.

De acordo com o filósofo ganês, tal recorrência à tradição foi gestada pelos ditames europeus sob o mote nação-literatura, "pois parte do que era considerado óbvio por esses escritores e pela cultura superior da Europa da época era que as novas literaturas das novas nações deviam ser anticolonialistas e nacionalistas" (APPIAH, 2007, p. 209). Portanto, a busca pela representação idealista da África ficou relegada apenas ao plano ideológico importado da Europa.

O rompimento com essa receita Ocidental começa com o pensamento antinativista e a literatura produzida no continente passa a ter o ser humano como tema. Com a superação desse projeto nacionalista de construir uma África imaginária, a produção literária tem agora um “apelo a um certo respeito simples pelo sofrimento humano, numa revolta fundamental contra o sofrimento interminável dos últimos trinta anos" (APPIAH, 2007, p. 213). Esses mesmos trinta anos, embora vividos aparentemente independentes das metrópoles europeias, não foram capazes de mudar os efeitos brutais da colonização.

Com isso, o projeto literário torna-se cada vez mais político e o livro de contos Vozes anoitecidas, de Mia Couto, escritor moçambicano, publicado em 1987, é um exemplo das produções que começaram a surgir, no continente, bem antes dos anos 80 do século passado. Esse livro está repleto de personagens sem voz, numa África que era e ainda é palco de disputas políticas e econômicas ocidentais.

Essa nova literatura, voltada para o humanismo, pode ser teorizada por aquilo que Appiah afirma sobre o pós-colonialismo: "um pós que 
contesta as narrativas legitimadoras anteriores. E as contesta em nome de vítimas sofredoras de 'mais de trinta repúblicas'. Mas contesta-as em nome do universal ético, em nome do humanismo" (APPIAH, 2007, p. 216). Tal proposição se faz presente na literatura de Mia Couto e, em especial, no seu livro, anteriormente citado, Vozes anoitecidas, do qual extraímos o conto "O dia em que explodiu Mabata-bata" para verificar como os traços do que a crítica literária denomina como pós-colonialismo podem ser identificados.

Em Moçambique, o projeto edificante das narrativas nativistas das literaturas anticoloniais africanas desaparece para dar lugar a uma série de estórias que Venâncio, a propósito do assunto, apresenta:

Os regimes instituídos na senda do nacionalismo, os processos de modernização então despoletados, não correspondem às expectativas criadas no período de pré-independência. $\mathrm{E}$ é no seio das elites que haviam pugnado pela independência dos seus países que nasce a frustração. Uns tantos, desiludidos com o uso que os seus ex-correligionários fazem do poder, afastam-se deles e criticam-nos. A literatura passa a ser a via privilegiada para a expressão desse descontentamento (VENÂNCIO, 1992, p. 9).

É a desilusão com as promessas não cumpridas, ocasionadas pela traição do governo, instalado após a independência moçambicana, que passa a ocupar as temáticas das literaturas produzidas em Moçambique. A produção literária reflete todo o mal-estar gerado pela decepção com o novo regime e os escritores, como Mia Couto, abrem as portas de seus textos para que entrem todos aqueles que foram esquecidos após a liberação do país, as "vozes anoitecidas".

\section{O PÓS-COLONIALISMO E AS LITERATURAS AFRICANAS DE LÍNGUA PORTUGUESA}

Como o pós-colonialismo poderia ser uma forma de olhar para as literaturas africanas? O termo surgiu a partir dos anos 70 do século passado para denominar a forma como a colonização afetou, culturalmente, os povos que viveram tutelados pelos estados europeus, em especial, França, Inglaterra e Portugal. A crítica do pós-colonialista "considera as formas e os temas imperiais caducos, esforça-se por combater e refutar as suas categorias, e propor uma nova visão de um mundo, caracterizado pela coexistência e negociação de línguas e culturas" (LEITE, 2003, p. 11). O que passa a ocupar a cena é a crítica a traços do colonialismo, buscando, mesmo em textos do período, marcas das relações de poder e subordinação entre o colonizado e o colonizador, trazendo-as para o palco e desnudando as representações de poder do estado colonial em seu processo "civilizatório".

Ana Mafalda Leite expõe que "os estudos teóricos do pós-colonialismo tentam enquadrar as condições de produção e os contextos socioculturais em que se desenvolvem as novas literaturas" (LEITE, 2003, p. 13). 
Essas obras, surgidas nesses territórios até então ocupados pelo Ocidente, são observadas sob uma perspectiva política, em que o local de fala do autor tem que ser compreendido quando se lê o texto literário pós-colonial. Não é possível olhar para essa literatura, através de conceitos da crítica literária ocidental que se baseia no seu próprio cânone. Tal procedimento esvaziaria muito do potencial estético da literatura africana. Essa produção literária tem, usando um termo da biologia, uma relação simbiótica com o contexto sociocultural de onde emerge. Conforme Bhabha, "muda-se a posição da enunciação e as relações de discurso dentro dela, não é só o que é dito, mas donde é dito; não é apenas a lógica da articulação, mas o topos a enunciação" (BHABHA, 2001, p. 560). "Quem” está enunciando, "de onde" enuncia e "o que" enuncia têm que ser observados na literatura pós-colonial. Não é possível ler "O dia em que explodiu o Mabata-taba" sem observar a articulação do narrador com o contexto histórico.

Stuart Hall, falando sobre o pós-colonialismo em seu ensaio "Quando foi o pós-colonial? Pensando no limite", faz uma série de questionamentos importantes sobre a temporalidade do pós-colonial e os limites que o distinguem do colonialismo, do neocolonialismo, do Terceiro Mundo e do imperialismo. Ora refutado, ora aclamado, ora visto com cautela, o pós-colonialismo tem despertado, por vezes, acirradas discussões teóricas. Hall, nesse ensaio, vale-se de dois teóricos, a iraquiana Ella Shohat e o historiador turco Arif Dirlik, para discutir a conceituação do termo.

Shohat, de acordo com o teórico jamaicano, define, em seus argumentos, que “o 'pós' significa 'passado': algo definitivamente concluído e fechado” (HALL, 2003, p. 102). Nessa visão, o colonialismo é algo superado e suas marcas deixam de existir, como num passe de mágica, numa virada, apagando-se com isso a história. Como se fosse possível, no meio de uma narrativa, recomeçá-la, desfazendo-se de todos os personagens anteriores. A história não permite esse recomeço, pois esta é uma postura ideológica favorável às metrópoles colonizadoras.

Um exemplo desse apagamento que o "pós" pode suscitar leva a uma perspectiva perigosa quando se fala sobre a hibridez e o sincretismo atrelados à identidade, pois "a celebração do sincretismo e hibridez de per $s i$, se não articulada em conjugação com questões de hegemonia e relações de poder neocoloniais, corre o risco de parecer santificar o fait accompli da violência" (SHOHAT, 1996, apud MATA, 2008, p. 5). Fora de seus contextos históricos e sociais, esses termos dissimulariam toda a brutalidade da colonização e consumariam, como um fato normal, a violência do processo colonial.

Inocência Mata oferece como exemplo desse fato, a propósito da presença de Portugal em Angola - a "intenção relativista na argumentação que suporta a teoria do 'neo-luso-tropicalismo', agora denominado crioulidade, formulação que se quer explicativa da presença portuguesa, 
considerada substrato da angolanidade, equiparada a identidade nacional" (MATA, 2008, p. 26). Essa celebração disfarçada, promotora do imperialismo lusitano, foi importada do Brasil pelo salazarismo português que veio buscar, no luso-tropicalismo de Gilberto Freyre, uma perspectiva positiva da imagem da mestiçagem brasileira. O propósito da colonização portuguesa de ocupação territorial por meio da violação de corpos é escondido pelo advento positivo da mestiçagem. Assim, "sincretismo" e "hibridez" operariam como construções ideológicas, máscaras de aceitação pacífica posta nas faces dos colonizados pelos colonizadores.

Ao voltarmo-nos para tais termos, citados acima, não devemos nos esquecer de que eles representaram "estratégias outras de sobrevivência cultural empreendidas pelos colonizados, como seja a reciclagem de línguas culturais dentro da tradição" (MATA, 2008, p. 27). Isso pode ser notado, na literatura de Mia Couto, em suas estratégias linguísticas de recriação da língua portuguesa em Moçambique. O escritor desordena o sintático, oralizando a escritura, povoando ou descolonizando o léxico com expressões das línguas moçambicanas locais. Tal estratégia pode ser observada no conto de Mia Couto.

Voltando, agora, para a discussão do termo "pós-colonial" e sua polêmica definição, Stuart Hall coloca que para Dirlik “o pós-colonial menospreza grosseiramente' a estruturação capitalista do mundo moderno" (HALL, 2003, p. 103). O crítico jamaicano avalia a reflexão de Dirlik como "um certo saudosismo" por posições binárias, que dividiam o mundo entre A e B, no campo político. Tal constatação é feita a partir da observação de que hoje as relações políticas internacionais não são mais possíveis segundo uma visão binária do mundo, porque "as posições políticas não são fixas, não se repetem de uma situação histórica a outra" (HALL, 2003, p. 104). Tanto é que o contexto histórico do qual emergem "as vozes anoitecidas" de Mia Couto representa o Moçambique pós-independência, cujo projeto político colocou à margem parte de seu povo.

O uso inadequado do conceito, aplicado sem o devido cuidado por todos que se apropriam dele, sem levar em conta "as distinções a serem feitas, [...] tem causado o enfraquecimento do valor conceitual do termo" (HALL, 2003, p. 106), e sugere lacunas que gerariam imensas críticas, tais como as propostas por Shohat e Dirlik. A generalização é um flanco perigoso por onde a crítica pós-colonial descuidada sofre inúmeros ataques.

Diante dessa abordagem, onde fica a literatura africana de língua portuguesa dentro do pós-colonialismo? Para Inocência Mata,

o autor - em pleno domínio do que diz, ou faz as suas personagens dizerem - psicografa os anseios e demônios de sua época, dando voz àqueles que se colocam, ou são colocados, à margem da 'voz oficial': daí pode pensar-se que o indizível de uma época só encontra lugar na literatura (MATA, 2008, p. 21). 
O escritor das literaturas africanas de língua portuguesa pode ser um porta-voz de sua época, aquele através do qual se manifestam as "vozes anoitecidas". O texto literário passa a ser o local por onde escapam as representações sociais. A literatura e a sociedade começam a andar pelo mesmo caminho, possibilitando a releitura do colonialismo pela ótica do narrador.

Em prefácio ao livro Vozes anoitecidas, o poeta moçambicano Luis Carlos Patraquim observa:

fico-me pelo particular dos teus contos, por essa opção tua, minudente, de quereres iluminar o lado de sombra, só aparentemente comezinho, desta saga histórica que nos envolve. Vergados ao discurso grandíloquo é bom esta descolonização da palavra, este experimentar de estruturas narrativas, este também sentencioso - mais persuasivo do que impositivo - modo de nos recordar as pequenas verdades dos pequenos e esquecidos personagens de cuja soma total, derrogados do que não interessa do seu valor intrínseco, o Discurso da História se faz (PATRAQUIM, 2008, p.16-17).

O narrador, neste livro, apresenta histórias daqueles que são excluídos do discurso oficial, os que ficaram à margem da empreitada da independência do país. A marca de sua narrativa envolve a "descolonização da palavra", como uma tomada de posicionamento político-linguístico. Mas como enunciar por intermédio de uma língua que traz o nome do país colonizador? Essa é uma das grandes discussões em torno da produção literária pós-colonial.

As literaturas africanas lusófonas, mesmo antes da fase pós-colonial, já se valiam do hibridismo linguístico, ou seja,

escritores como Luandino Vieira, Uanhenga Xitu, José Craveirinha, $[. .$.$] mostram que vários modos de supressão da$ norma do português metropolitano, de que resultaram várias combinatórias exemplares do hibridismo linguístico, foram uma das constantes mais significativas da textualidade africana de língua portuguesa (LEITE, 2003, p. 15).

Como já dissemos anteriormente, mesmo antes da independência dos países africanos tutelados por Portugal, a subversão da língua, tanto no campo semântico quanto no sintático e lexical, já era uma constante. Tal estratégia textual foi uma marca significativa de resistência e afirmação da identidade das culturas africanas. Não houve uma maneira de a língua portuguesa ficar imune a esse processo.

Segundo Ana Mafalda Leite, "a enunciação dos legados culturais outros faz-se através do enunciado, que cumula e concentra, numa geologia estratificada que atinge a sintaxe, os ritmos híbridos da textualidade oral" (LEITE, 2003, p. 21). Assim, tem-se o advento da oratura enquanto estratégia textual para representar a África em contraste com a escritura europeia. Pode se observar também essa forma de posicionamento dos es- 
critores - e, nesse caso em questão, de Mia Couto - como uma resistência estratégica em que o estético está ligado a valores ético-humanistas.

A busca pela tradição, até então silenciada no texto literário, é uma constante na produção literária que se vale da oralidade como forma textual, mas "grande parte desses escritores sabe, contudo, da impossibilidade de as tradições poderem ser resgatadas em sua inteireza primeva" (SECCO, 2008, p. 28). O que é trazido para o texto é uma engenhosidade estética que "com o domínio de modernas técnicas de fingimento literário, refletem sobre o próprio ato de criação e, muitas vezes, retrabalham provérbios, adivinhas, máximas, criando situações simuladas de oratura na cena textual" (SECCO, 2008, p. 28). Assim, o moderno, representado pela escrita, dialoga com o tradicional, representado pela oralidade.

Em Mia Couto, temos o uso - com maestria - dessas técnicas narrativas com as quais são construídos muitos de seus contos. A representação da oralidade e mesmo a invenção de palavras, o que Fernanda Cavacas (1999) chama de "brincriação vocabular", são exemplos encontrados na literatura do moçambicano.

Tal representação é um elemento pelo qual a crítica define a "especificidade e autonomização destas literaturas em relação às suas origens coloniais" (LEITE, 2003, p. 43). A busca pelas matrizes locais da cultura oral e a sua transposição para a escritura são uma forma única pela qual a literatura se desprenderia da influência colonial. É pelo resgaste da tradição e pela sua constante renovação que autores como Mia Couto vão trilhando o caminho da escrita. Trazer para o texto "os intertextos culturais, orais, indígenas" (LEITE, 2003, p. 44) marca uma tentativa de colocar o caráter libertário de autores como Couto em suas fontes coloniais.

No livro Vozes anoitecidas, publicado em 1987, o escritor, como um griot moderno, conta histórias e coloca em evidência toda sorte de personagens numa "tessitura humano-social" (cf. CRAVEIRINHA, 2008, p. 9) marcada, muitas vezes, pela recorrência ao fantástico, ao absurdo, na tentativa de retratar uma forma pela qual as personagens vivem o real.

\section{O USO DE ELEMENTOS FABULOSOS COMO ESTRATÉGIA TEXTUAL}

Nessa direção, falando a propósito das literaturas africanas de língua portuguesa, Inocência Mata afirma que "outra marca dessa transformação literária [...] componente da sua (nossa) pós-colonialidade, é o recurso ao insólito, ao absurdo, ao fantástico como estratégia de enfrentamento do real" (MATA, 2000, p. 5). Couto usa esse recurso em muitos dos contos de Vozes anoitecidas. Os seus enredos trazem esse fantástico das situações humanas "cuja lógica se mede não poucas vezes pelo absurdo, por um irrealismo, conflitantes situações" (CRAVEIRINHA, 2008, p. 10) para apresentar a realidade moçambicana pós-colonial. 
O conto "O dia em que explodiu Mabata-bata" narra a estória de um garoto órfão, chamado Azarias, que vive, junto com sua avó, sob a tutela de seu tio Raul desde a morte dos pais. Esse mesmo tio explora-o, fazendo com que cuide do rebanho durante todo o dia. Então, um dos bois, o Mabata-bata, que seria destinado como uma prenda de casamento do tio para sua noiva, pisa numa mina terrestre e explode. Azarias, tendo a palavra azar representada no próprio nome, não entende o fato e passa a creditar ao ndlati, uma ave mitológica que representa o relâmpago, a causa da explosão do boi. Com medo de ser punido pelo tio, que não acreditaria em sua versão, Azarias se esconde, juntamente com os bois, no rio. Preocupado com seus bois, após ter sido avisado por soldados sobre a explosão de uma mina que tinha matado uma peça de seu rebanho, o tio do menino sai a sua procura e é seguido, contra a sua vontade, pela avó Carolina. O garoto atende aos chamados afetivos de sua avó, após a falsa promessa de seu tio de que ele poderia frequentar a escola no ano vindouro. Para ter seus bois de volta, Raul se prontifica, falsamente, a atender esse desejo do órfão. Quando Azarias vai ao encontro de seus parentes, correndo pelo areal do rio, pisa numa mina e acaba morrendo. Nesse momento, crê estar sendo levado, nas asas do ndlati, para sua morada na montanha.

Numa conferência realizada em 2005, em Deza Traverse, na Suíça, por ocasião dos 30 anos da independência de Moçambique, o escritor moçambicano falou:

No meu país o espectro do terrorismo não começou com o Onze de Setembro. Milhares de crianças estão desde há mais de vinte anos espreitando com medo o chão que vão pisar. Mais de um milhão de minas antipessoais foi semeada durante a guerra. Milhares desses engenhos mortais continuam semeando o terror no seio de cidadãos inocentes. Quantos dos países ricos que se mobilizam contra terrorismo assinaram a convenção para o banimento da produção de minas? (COUTO, 2005, p. 202)

Pela cronologia, o texto foi pronunciado em 2005, enquanto Vozes anoitecidas é publicado em 1987. Assim sendo, o autor já tinha dito antes, pela literatura, aquilo para que chama a atenção do mundo na conferência na Suíça: a realidade cruel do rescaldo da guerra civil que, quando não tirou a vida, deixou mutiladas muitas crianças moçambicanas transforma-se em tema de conto. Como se dá, portanto, essa construção?

Como já falamos anteriormente, o contador de histórias, Mia Couto, deixa reverberar pelas suas estratégias textuais, pelo "modo vívido de contar, um griot comprometido com a verdade de seus personagens e do mundo trágico em que é dado a habitar" (SANTILLI, 2003, p. 170). Em seus contos, que ele prefere que sejam chamados de histórias, Mia Couto vai griotizando a cena e misturando realidade e fantasia numa história cujo título já remete ao universo da lenda, pois todos querem saber sobre o ocorrido em "O dia em que explodiu o Mabata-bata". 
Instaura-se, pois, todo o jogo narrativo que passa a ter duas versões. Essas "duas óticas contrárias correm paralelas até a cena final: aquela do menino, em cuja versão mítica as desgraças ligam-se à ave ndlati, e a versão da outra faixa etária - a dos adultos - que se constrói com informantes históricos, sobre minas que explodem" (SANTILLI, 2003, p. 169). Se Azarias titubeia, no início, não tendo certeza se foi o ndlati que causou a explosão do boi, "Mas quem podia acreditar?" (COUTO, 2008, p. 44), no final do conto, a dúvida já não existe, pois ele abraça a ave e segue com ela.

No universo de Azarias, a existência do ndlati faz parte do imaginário cultural. Não só ele mas todos, no universo do conto de Couto, estão ligados às crenças animistas de sua cultura, tal como podemos constatar no trecho: "Uma vez foi preciso chamar as ciências do velho feiticeiro para escavar aquele ninho e retirar os ácidos depósitos” (COUTO, 2008, p. 44). Portanto, apesar da colocação da pesquisadora brasileira de que Azarias encontra-se inscrito "numa faixa etária propicia a borrar os limites do real e o suposto" (SANTILII, 1999, p. 104), não é possível afirmar que ele, por ser criança, não tenha certeza dos limites entre a realidade e o imaginário, dado que vive em meio a um universo de crenças animistas em que o uso da magia, como o conto deixa entrever, na utilização da expressão "ciências do velho feiticeiro", é uma constante cultural na qual estão inseridos os personagens da narrativa.

Quando Inocência Mata (2000) se refere ao uso do fantástico como uma estratégia textual pela qual Mia Couto tematiza o real, temos que pensar como se caracteriza esse recurso literário no conto. Se levarmos em conta as proposições de Todorov, em sua obra Introdução à literatura fantástica, a respeito do modo como acontece o fantástico, o estranho, o maravilhoso, nos textos literários, devemos pensar que o crítico aplica as suas definições em textos do cânone ocidental. Quando se trata de textos de literatura africana, tais categorias descritas por Todorov revelam-se "insuficientes para abarcar artisticamente a realidade sociocultural de povos que não abdicam de suas tradições de cunho animista, ao mesmo tempo em que se inserem no sistema capitalista moderno" (SARAIVA, 2007, p. 12).

Se o fantástico literário implica quebrar as leis da racionalidade, as leis naturais, pode-se pensar no uso dessa categoria por Mia Couto:

como meio de criticar o real opressor e de subverter os cânones da racionalidade europeia. Seus textos fundam uma semiose libertadora, cuja ação, por intermédio de representações oníricas, faz aflorar o imaginário cultural popular, que foi censurado tanto no período colonial, como nos primeiros anos após a libertação, quando a orientação marxista ortodoxa do Governo da Revolução proibia, de modo geral, as manifestações religiosas. (SECCO, 2006, p. 72)

O mundo racional europeu silenciou as crenças animistas africanas descaracterizando o animismo pela lógica racionalista. Nessa perspectiva etnocêntrica, segundo a qual apenas não civilizados ou mesmo primi- 
tivos não separam o mundo racional do universo de crenças ditas bárbaras, a cultura que usava as "ciências do velho feiticeiro" foi calada. Como verificar, então, essa literatura, usando uma teoria ocidental fundamentada em textos canônicos da cultura europeia?

Conforme o célebre texto do teórico da literatura fantástica,

o estranho não cumpre mais que uma das condições do fantástico: a descrição de certas reações, em particular, a do medo. Relaciona-se unicamente com os sentimentos das pessoas e não com um acontecimento material que desafia a razão (TODOROV, 1981, p. 27).

No caso aqui analisado, Azarias crê na existência - que faz parte da sua cultura - do ndlati, mesmo quando o narrador deixa claro que a explosão do boi foi ocasionada pelo fato de o animal ter pisado em uma mina: "Vimos comunicar o acontecimento: rebentou uma mina esta tarde. Foi um boi que pisou. Agora, esse boi pertencia daqui" (COUTO, 2008, p. 45). Dessa forma, o medo de Azarias não é pela presença do ndalti, mas pela reação do tio que não acreditaria nele. Essa versão é trazida de forma oficial, pela boca dos soldados, com o objetivo de retratar a racionalidade do fato. É como se representasse a sua oficialidade, a narrativa do real, a sua racionalidade, ligada ao contexto da guerra, escondido do órfão pelo narrador, ou seja, não se permite que o pequeno órfão saiba da existência de tal realidade.

Se pensarmos nas proposições de Secco (2006), o estado aqui funciona como um censor das manifestações religiosas animistas. Toda possível dúvida que o leitor possa ter lhe é retirada pela fala do soldado sobre a existência de minas terrestres. No caso de Moçambique, esse silenciamento cultural, ainda conforme Secco (2006), foi realizado duplamente: primeiro pela colonização portuguesa e depois pelo modelo comunista importado junto aos europeus no período da independência. Tal modelo de orientação marxista, transplantado voluntariamente para Moçambique, desprezou toda a tradição religiosa africana; procurou substituí-la pelo racionalismo europeu, até mesmo criminalizando-a. Nessa perspectiva, o uso do fantástico por Mia Couto passa a ter um caráter de crítica social e de autonomia literária frente ao racionalismo europeu.

No mundo do tio Raul, não há a possibilidade da crença animista, pois Azarias teria que prová-la. Essa afirmação encontra sua sustentação no trecho: "Havia de querer ver o boi falecido, ao menos ser apresentado uma prova do desastre. Já conhecia bois relampejados: ficavam corpos queimados, cinzas arrumadas a lembrar o corpo. O fogo mastiga, não engole de uma só vez, conforme sucedeu" (COUTO, 2008, p. 44). Nesse mundo, que não acolhe a orfandade, Azarias é explorado e mesmo animalizado pelo escárnio do tio, cujas palavras comprovam tal afirmação: "Este, da maneira que vive misturado com a criação há-de se casar com uma vaca" (COUTO, 2008, p. 45). Do personagem tudo é retirado: primeiro os pais são mortos (observando o contexto do conto, podemos inferir que essa morte pode ter 
sido ocasionada pela guerra); depois o tio não o acolhe, mas obriga-lhe a uma vida de trabalho árduo, tal como ilustra a seguinte passagem: "O serviço arrancava-o cedo da cama e devolvia-o ao sono quando dentro dele não havia resto de infância" (COUTO, 2008, p. 45). Ele não é um ser, ninguém quer "saber de sua alma pequenina, dos sonhos maltratados" (COUTO, 2008 , p. 45). No universo do tio, o boi explodido tem mais valor que Azarias, o que pode ser sustentado a partir da metáfora, "os ossos eram moedas espalhadas" (COUTO, 2008, p. 43), que ressalta o valor financeiro do boi em relação à criança. Essa sustentação pode ser fortalecida na narração de que, quando o tio é informado pelos soldados sobre a morte do animal, sai pela noite, correndo o risco de pisar em uma mina ou encontrar bandidos. Ele se arrisca por seus animais, não pelo sobrinho, pois "é preciso juntar os bois enquanto é cedo" (COUTO, 2008, p. 46).

Azarias é totalmente espoliado pela vida e quem lhe restitui o direito ao sonho é o narrador. Assim, "Couto faz uso de uma grande variedade de fontes culturais em seu conto particularmente comovente que, em essência, pretende restaurar o direito de Azarias sonhar no meio da terrível guerra civil que vitimou crianças" (ROTHWELL, 2004, p. 112).

Já que Azarias foi privado de tudo, resta-lhe viver em meio aos animais e, "analogizando a situação de risco do animal e do homem" (SANTILLI, 1999, p. 103), acaba como Mabata-bata. Cabe ao narrador permitir, a ele, o mundo onírico em que pode imaginar e acreditar nas palavras do tio, restaurando a confiança naquele que devia protegê-lo. Desta maneira, "a criança morre acreditando falsamente que seu sonho de ir à escola será concedido a ele pelo tio e nunca sofrerá uma desilusão ao descobrir que seu parente mentiu para ele" (ROTHWELL, 2004, p. 112). Através da engenhosidade da construção das duas versões da matéria narrada, o pequeno pastor não se decepcionará com a mentira do adulto, pois crê naquilo que lhe foi prometido, tanto que só "saiu da sombra" (COUTO, 2008, p. 48) para ir ao encontro de uma vida de criança normal.

Nesta perspectiva ilusória, no final do conto, o "abraço final/fatal de Azarias é uma alegoria da pulsão pela liberdade" (SANTILII, 1999, p. 104), já que é nas asas da ave mitológica que Azarias vai, quiçá, voando como os pássaros. A intervenção do narrador, embaralhando a leitura do conto, faz com que "o leitor se pergunte, então, se a explosão de uma real segunda mina aí aconteceu, ou tenha que se definir pela versão em que vai embarcar, desta vez" (SANTILLI, 2003, p. 170).

Nessa mistura de perspectivas narrativas, como já colocamos anteriormente, o conto corre por duas vertentes que misturam o mundo da dura realidade com o mundo do fantástico, caracterizando, possivelmente, uma preferência de Couto.

Pode ser justificado, dessa maneira, o uso do fantástico, proposto por Inocência Mata (2000) como uma maneira da literatura africana de língua portuguesa colocar-se frente a uma realidade brutal. 


\section{CONSIDERAÇÕES FINAIS}

Por fim, podemos pensar que a utilização, no conto, de um mito do povo tsonga do sul de Moçambique, o ndlati, ${ }^{1}$ é uma estratégia em que o narrador vale-se da função de griot para trazer para o conto

o fantástico, o mundo povoado de animais astutos e também monstros horrendos e onde ocorrem situações mais inquietantes, transmissível e enriquecido historicamente, é a escola de valores e forma de desenvolver capacidades intelectuais e criativas (NAVARRO, 1998, apud SECCO, 2008).

Ao narrador compete o papel de recuperar o imaginário popular e valer-se dele para subverter o real e, quiçá, usando aquele humanismo ético do pós-colonialismo aludido por Appiah (2007), falar dos horrores provocados pelos "monstros horrendos" que são as minas terrestres.

O escritor moçambicano dá a conhecer o mito do ndlati narrando-o quase como um registro etnográfico.

Talvez o ndlati, a ave do relâmpago, ainda rodasse os céus. Apontou os olhos na montanha em frente. A morada do ndlati era ali, onde se juntam os todos rios para nascerem da mesma vontade da água. O ndlati vive nas suas quatro cores escondidas e só se destapa quando as nuvens rugem na rouquidão do céu. É então que o ndlati sobe aos céus, enlouquecido. Nas alturas se veste de chamas, e lança o seu voo incendiado sobre os seres da terra. Às vezes atira-se no chão, buracando-o. Fica na cova e a deita a sua urina (COUTO, 2008, p. 44).

É sabido que "parte significativa do material temático fabuloso de Terra Sonâmbula se fundamenta nas tradições dos povos do sul de Moçambique" (LEITE, 2003, p. 51). Assim sendo, o autor já experimentava, nesse conto, escrito antes mesmo de seu mais conhecido romance, Terra Sonâmbula, a estratégia de "intertextualização do gênero oral de entretenimento ritual diário” (LEITE, 2003, p. 52) com a sua matéria narrativa e mostrava, para todos, a cultura de um país, resgatando uma tradição.

O elemento fabuloso é trabalhado para contar histórias e usado como uma forma de abraçar no invólucro o menino, talvez protegê-lo de um real absolutamente incompreensível e brutal: "O pequeno pastor engoliu aquele vermelho, era o grito do fogo estourando. Nas migalhas da noite viu descer o ndlati, a ave do relâmpago" (COUTO, 2008, p. 48). O horário aqui é significativo, pois

o imaginário é evocado normalmente à noite, à volta da fogueira, rearticulando o verossímil e o inverossímil, o verdadeiro e o falso, fazendo surgir situações antes tidas como impossíveis, numa dialética que não explica o mundo, mas procura imbuir a sociedade de respeito [...] pelos valores culturais que lhe são próprios (NAVARRO, 1998 apud SECCO, 2008). 
E é na noite que o griot Mia Couto, trazendo para a escritura a sabedoria oral ancestral, transmitida pelo ato de contar, mistura versões narrativas do real e do imaginário sobre a história de "O dia em que explodiu o Mabata-bata”. Toda a tradição cultural do moçambicano é apresentada para narrar a história de uma criança órfã, abandonada pelo seu parente e resgatada, pela sua própria imaginação, de uma morte brutal.

\section{REFERÊNCIAS BIBLIOGRÁFICAS}

APPIAH, Kwame. A. Na casa do pai. A África na filosofia da cultura. Rio de Janeiro: Contraponto, 1997.

CRAVERINHA, José. Prefácio à edição portuguesa. In: COUTO, Mia. Vozes anoitecidas. 9. ed. Lisboa: Caminho, 2008.p. 9-12.

COUTO, Mia. Moçambique - 30 anos de Independência: no passado, o futuro era melhor? Revista Via Atlântica, São Paulo, n. 8, p. 191-204, 2005.

. Vozes anoitecidas. 9. ed. Lisboa: Caminho, 2008.

HALL, Stuart. Da diáspora: identidades e mediações culturais. Belo Horizonte: Editora UFMG, 2006.

LEITE, Ana Mafalda. Literaturas africanas e formulações pós-coloniais. Lisboa: Edições Colibri, 2003.

MATA, Inocência. A crítica literária africana e a teoria pós-colonial: um modismo ou uma exigência? Revista $O$ Marrare. Rio de Janeiro, n. 8, p. 20-34, 2008.

. O pós-colonial nas literaturas africanas de língua portuguesa. In: X CONGRESSO INTERNACIONAL DA ALADAA- CULTURA, PODER E TECNOLOGIA: ÁFRICA E ÁSIA FACE À GLOBALIZAÇÃO, 2000, Rio de Janeiro. Disponível em: http://bibliotecavirtual.clacso.org.ar/ ar/libros/aladaa. Acesso em: 12 de Junho de 2011.

PATRAQUIM, Luis Carlos. Como se fosse um prefácio. In: COUTO, Mia. Vozes anoitecidas. 9. ed. Lisboa: Caminho, 2008. p. 13-17.

ROTHWELL, Phillip. A postmoderm nationalist: truth, orality and gender in the work of Mia Couto. Lewisburg: Bucknell University Press, 2004.

SANTILLI, Maria Aparecida. O fazer-crer, nas histórias de Mia Couto. Revista Via Atlântica. São Paulo, n. 3, p. 99-109, 1999.

. Paralelas e tangentes: entre literaturas de língua portuguesa. São Paulo: Arte \& Ciência, 2003.

SARAIVA, Sueli S. O realismo animista e o espaço não-nostálgico em narrativas africanas de língua portuguesa. In: XI ENCONTRO REGIONAL 
DA ABRALIC, 2007, São Paulo. Disponível em: <http://www.abralic.org. $\mathrm{br} / \mathrm{htm} /$ congressos/anais-eventos.htm >. Acesso em: 2 de agosto de 2011.

SECCO, Carmem L. Tindó. A magia das letras africanas: ensaios sobre as literaturas de Angola e Moçambique e outros diálogos. 2. ed. Rio de Janeiro: Quartet, 2008.

- Mia Couto: o outro lado das palavras e dos sonhos. Revista Via Atlântica. São Paulo, n. 9, p. 71-84, 2006.

TODOROV, Tzvetan. Introdução à literatura fantástica. São Paulo: Perspectiva, 1981.

VENÂNCIO, José Carlos. Literatura e poder na África lusófona. Lisboa: Ministério da Educação. Instituto de Cultura e Língua Portuguesa, 1992.

Recebido para publicação em 15/05/2014

Aprovado em 17/09/2014

\section{NOTAS}

1 De acordo com Junod (1996 apud SECCO, 2008), é chamado “o galo do céu, a ave do relâmpago e do trovão" 